Bull. Mater. Sci., Vol. 2, Number 3, August 1980, pp. 177-180. (C) Printed in India.

\title{
Magnetic properties of a mischmetal-cobalt alloy
}

\author{
R A TEWARI \\ Metallurgy Division, Materials Science Centre, Indian Institute of Technology, \\ Kharagpur 721 302, India
}

MS received 15 May 1980

\begin{abstract}
The magnetic properties of a mischmetal-cobalt alloy are studied. A mischmetal- $64 \%$ cobalt alloy was melted in induction furnace under a protective atmosphere of argon. The melt was solidified in a magnetic field of $7 \mathrm{kOc}$, and cooled to a temperature of $950^{\circ} \mathrm{C}$ and was thereafter quenched in water. Specimens of suitable dimensions were machined, heat-treated in the temperature range 1000$1100^{\circ} \mathrm{C}$ for various lengths of time and the magnetic properties evaluated. The $(\mathrm{BH})_{\text {nax }}$ value was $10.3 \mathrm{MGOe}$ which was associated with a $B_{r}$ value of $7 \mathrm{kG}$ and $\mathrm{H}_{\mathrm{c}}$ value of $5 \mathrm{kOe}$. The results obtained offer feasibility to design new MM-Co magnets through developments in processing technique.
\end{abstract}

Keywords. Solidification; atmosphere quenching.

\section{Introduction}

The fabrication of rare-earth-cobalt magnets possessing high energy product obtained by liquid phase sintering methods has been well understood. For instance $\mathrm{Sm}-\mathrm{Co}$ has been reported to possess (BH) max $_{\max }$ of 20 MGOe (Buschow et al 1969). However, the cost of magnet based on pure rare-earth metals is high since the rare-earth constituents are expensive. It would be highly desirable to develop magnets possessing high energy product at a relatively lower cost. With this objective this study was undertaken with cerium mischmetal which is relatively cheaper and seems to be a potential component in conjuction with cobalt possessing a (BH) $\max _{\max }$ of $20 \mathrm{MGOe}$ (Strnat 1967). The main advantages in the development of $\mathrm{MM}-\mathrm{Co}_{5}$ magnets as compared with $\mathrm{Sm}-\mathrm{Co}_{5}$ are, lower raw materials cost, lower sintering temperatures and better mechanical properties.

Attempts to replace pure rare-earth metals either partially or entirely by mischmetal additions have been made by various investigators. An energy product of 15.2 MGOe (Martin et al 1971) has been reported by liquid-phase sintering method in an alloy containing equal parts of $\mathrm{Sm}$ and $\mathrm{MM}$ with cobalt. Improved magnetic properties (Kawaguchi et al 1970) have been obtained for a $\mathrm{Cu}-\mathrm{MM}-\mathrm{Co}$ alloy prepared by melting and casting method. $\mathrm{MM}^{-\mathrm{Co}_{5}}$ alloy prepared by isostatic pressing (without sintering) has given a (BH) $\max _{\max }$ of 3.1 MGOe (McCaig 1970), using liquid-phase sintering, a $(\mathrm{BH})_{\max }$ of $4.4 \mathrm{MGOe}$ (Benz et al 1971) has been 
achieved in $\mathrm{MM}-\mathrm{CO}_{5}$ magnets. In an $\mathrm{MM}-\mathrm{Co}_{5}$ alloy a $(\mathrm{BH})_{\max }$ of $8.8 \mathrm{MGOe}$ (Fellow et al 1972) has been achieved by liquid phase sintering method. Using a single melt approach (BH) max $_{\text {ax }}$ of 10-12 $\mathrm{MGO}_{\mathrm{e}}$ (Wells 1973) have also been reported. The present investigation is however confined to the development of magnetic properties of $\mathrm{MM}-\mathrm{Co}_{5}$ alloy.

\section{Experimental}

A mischmetal-64\% cobalt alloy was prepared by induction melting using a protective atmosphere of argon in alumina crucible. The melt was solidified in a magnetic field of $7 \mathrm{kOe}$, and cooled to a temperature of $950^{\circ} \mathrm{C}$ and thereafter quenched in water. During solidification and cooling the pole pieces were well protected against radiated heat by (a) cooling the pole pieces by water circulation through copper tubing wound on them, and (b) placing asbestos sheet in the form of cylinder opened at both ends to accommodate the crucible containing the melt. Specimens $5 \mathrm{~mm}$ in diameter and $10 \mathrm{~mm}$ in length were machined for heat treatments and magnetic measurements. Specimens were annealed between $1000^{\circ}$ $1100^{\circ} \mathrm{C}$ at $20^{\circ} \mathrm{C}$ intervals for a constant period of $60 \mathrm{~min}$ in an argon atmosphere. Further, the specimens were annealed ranging from $15 \mathrm{~min}$ to $120 \mathrm{~min}$ at some selected temperatures within the above specified range.

\section{Results and discussion}

Figure 1 shows the variation of coercive force with temperature. The maximum in coercivity is observed at $1020^{\circ} \mathrm{C}$ with an $\mathrm{H}_{c}$ value of $4.4 \mathrm{kOe}$. The decrea se of coercivity between $1000-1040^{\circ} \mathrm{C}$ is small. The coercivity, however, decreases fast by increase of temperature above $1040^{\circ} \mathrm{C}$. Figure 2 shows the variations of coercivity with time for the specimens annealed at $1020^{\circ} \mathrm{C}$. The coercivity decreases initially and then rises and approaches its maximum value of $5 \mathrm{kOe}$ in $60 \mathrm{~min}$. For the rest of the increase 1 periods of annealing the decrease of coercivity is slow.

Figure 3 shows that the $B_{r}$ value increases with increase in temperature but the increase is slow at higher temperatures. The variation of $B_{r}$ with time (figure 4) at $1040^{\circ} \mathrm{C}$ shows a maximum in $30 \mathrm{~min}$ reaching a value of $7 \mathrm{kG}$.

Figure 5 gives the variation of energy product $(\mathrm{BH})_{\max }$ with temperature. A peak in the curve is noted at $1040^{\circ} \mathrm{C}$ acquiring a value of $9.2 \mathrm{MGO}$. The variation of $(\mathrm{BH})_{\max }$ with time is shown in figure 6 which shows that $(\mathrm{BH})_{\max }$ has reached a value of 10.3 MGOe. Further decrease of $(\mathrm{BH})_{\max }$ with time is slow.

The response of the magnetic properties noted in this $\mathrm{MM}-\mathrm{Co}_{5}$ alloy appears to be dependent on the processing parameters associated with structural trans. formations occurring in this system. The structural changes occurring in this system are expected to be complex since the mischmetal is a cerium-rich alloy which, however, contains significant amounts of $\mathrm{La}, \mathrm{Nd}$ and $\mathrm{Pr}$. Moreover, it has already been reported (Buschow 1972, 1973) that all the $\mathrm{RCo}_{5}$ alloys where $\mathrm{R}$ is a rare-earth metal, undergo eutectoid reaction like $\mathrm{RCo}_{5} \rightarrow \mathrm{R}_{2} \mathrm{Co}_{17}+\mathrm{R}_{2} \mathrm{Co}_{7}$. Since $\mathrm{La}, \mathrm{Nd}, \mathrm{Pr}$ and $\mathrm{Ce}$ are present in mischmetal such reactions are expected to affect 

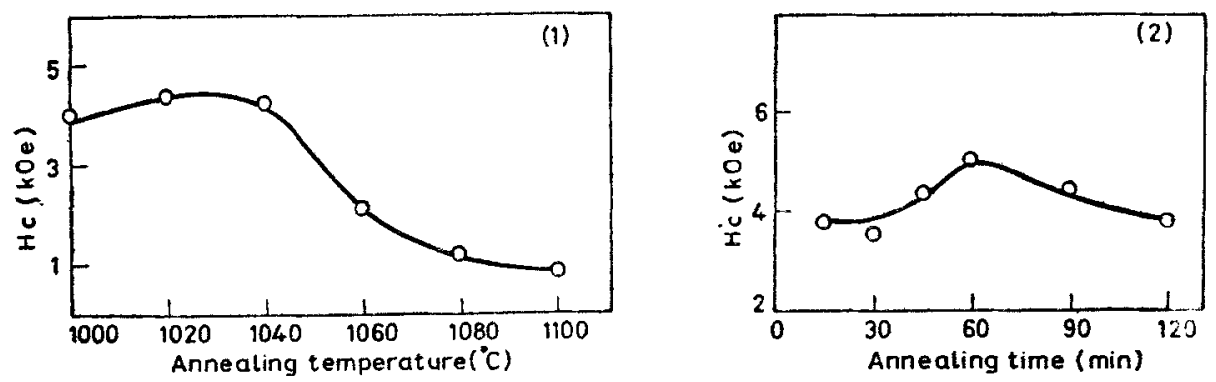

Figures 1 and 2. Variation of $H_{c}$ with 1. temperature $(60 \mathrm{~min}) ; 2$. time at $1020^{\circ} \mathrm{C}$.
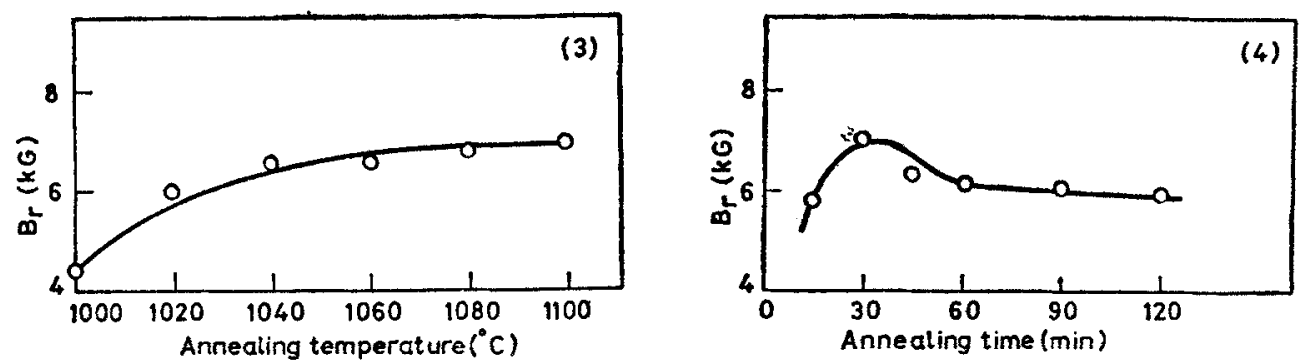

Figures 3 and 4. Variation of $B_{r}$ with 3 . temperature $(60 \mathrm{~min}) ; 4$. time at $1040^{\circ} \mathrm{C}$.
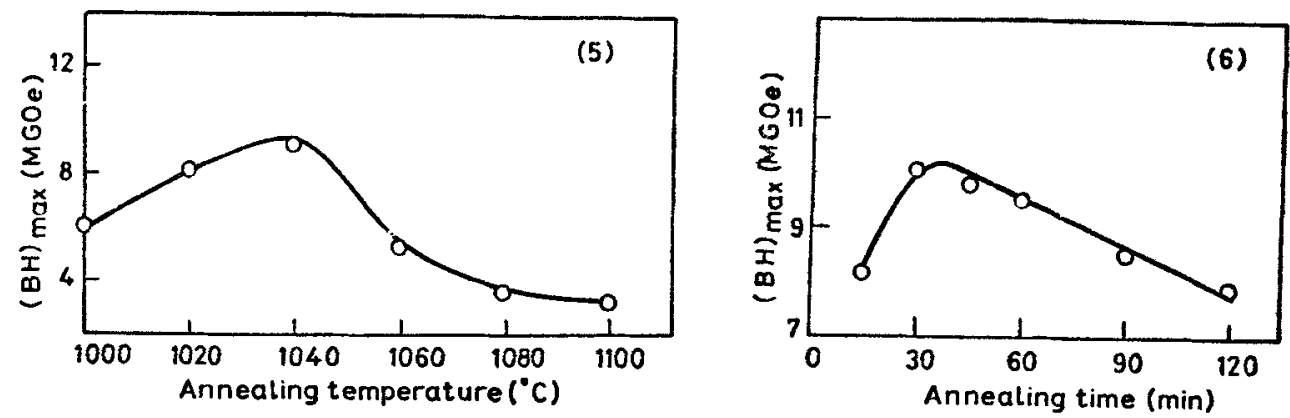

Figures 5 and 6. Variation of $(\mathrm{BH})_{\max }$ with 5 . temperature $(60 \mathrm{~min})$; 6. time at $1040^{\circ} \mathrm{C}$.

magnetic properties in a complex manner and hence precise interpretation of the magnetic behaviour becomes difficult. It is, however, felt that results of such complex reactions occurring during heat treatment in association with the processing variables are responsible for the response of the magnetic properties noted in the mischmetal-cobalt alloy under investigation, 


\section{Conclusions}

The process of solidification of the $\mathrm{MM}-\mathrm{Co}_{5}$ alloy in a magnetic field has yielded magnetic properties like $(\mathrm{BH})_{\max } 10.3 \mathrm{MGOe}, \mathrm{B}_{\mathrm{r}} 7 \mathrm{kG}$ and $\mathrm{H}_{\mathrm{c}} 5 \mathrm{kOe}$, and the process is expected to be economical compared to other fabrication methods.

\section{Acknowledgements}

The author would like to record the help received from the Head of the Department of Metallurgical Engineering, Indian Institute of Technology, Kharagpur, for facilities to carry out a part of the experimental work.

\section{References}

Benz M G and Martin D L $1971 J$ Appl. Phys. 421534

Buschow K H J, Nasterpad P A and Westendorp F F 1969 J. Appl. Phys. 404029

Buschow K H J 1972 J. Less Common Met. 29283

Buschow K H J 1973 J. Less Common Met. 31359

Fellows $\mathbf{C ~ J}$ and Johnson R E 1972 Cobalt No. $561+1$

Kawaguchi, Toranosuke, Yamoto, Hiroshi and Takata 1970 Nippon Kinzoku Gakaishi 341097

Martin D L and Benz M G 1971 Cobalt No. 5011

McCaig M 1970 F.E.E.E. Trans. Magnetics Mag. 6198

Ratnam D V and Wells M G H 1973 Conf. on magnetism and magnetic materials, Boston, Mass.

Strnat K 1967 Cobalt No. 36133

Wells M G H et al 1973 Conference on magnetism and magnetic materials Boston, Mass. 